\title{
Chemotherapy Induced Thrombocytopenia in Ewing Sarcoma, Implications and Potential for Romiplostim Supportive Care
}

\author{
Nawal Merjaneh ${ }^{1}$, Jennifer Young ${ }^{1}$, Avani Mangoli ${ }^{2}$, Mallery Olsen $^{3}$, Bhuvana Setty ${ }^{4}$, \\ Adam Lane $^{5}$, Rajaram Nagarajan ${ }^{6}$, Joseph Pressey ${ }^{1}$, and Brian Turpin ${ }^{1}$ \\ ${ }^{1}$ Cincinnati Children's Hospital Medical Center \\ ${ }^{2}$ Duke University \\ ${ }^{3}$ Nationwide Children's Hospital \\ ${ }^{4}$ Nationwide Children's \\ ${ }^{5}$ Cincinnati Childrenś Hospital Medical Center \\ ${ }^{6}$ Children's Hospital Cincinnati
}

October 21, 2021

\begin{abstract}
Background: Maintaining dose-dense, interval-compressed chemotherapy improves survival in Ewing sarcoma patients but is limited by myelosuppression. Romiplostim is a thrombopoietin receptor agonist that may be useful in the treatment of chemotherapy-induced thrombocytopenia (CIT). Methods: Patients aged between 3 and 33 years with Ewing sarcoma from 2010-2020 were reviewed. CIT was defined as a failure to achieve 75,000 platelets per microliter by day 21 after the start of any chemotherapy cycle. Fisher exact test was used for univariate analysis and Pearson's correlation coefficient was used for the association between continuous variables. Results: 27 out of 42 patients (64\%) developed isolated CIT, delaying one to four chemotherapy cycles per patient. CIT occurred during consolidation therapy in 24/27(88.9\%) and with ifosfamide/etoposide cycles in $24 / 27(88.9 \%)$. Univariate analysis failed to identify risk factors for CIT. The use of radiation approached significant ( $\mathrm{p}$ value $=0.056$ ). Ten patients received romiplostim. The median starting dose was 3 (range 1-5) mcg/ $\mathrm{kg}$. Doses were escalated weekly by $1-2 \mathrm{mcg} / \mathrm{kg}$ to $4-10 \mathrm{mcg} / \mathrm{kg}$ and continued throughout chemotherapy. A higher romiplostim dose was associated with a higher change in average platelet counts from baseline $\mathrm{r}=0.73(\mathrm{p}=0.04)$. No romiplostim-related adverse events were identified aside from mild headache. Conclusions: CIT is the primary reason for the inability to maintain treatment intensity in Ewing sarcoma. The concurrent use of romiplostim with chemotherapy is safe and feasible, and efficacy was associated with higher romiplostim doses.
\end{abstract}

\section{Hosted file}

Manuscript. final+Duke+NCH.DOCX available at https://authorea.com/users/442311/articles/ 542600-chemotherapy-induced-thrombocytopenia-in-ewing-sarcoma-implications-andpotential-for-romiplostim-supportive-care

\section{Hosted file}

TABLE 1-patient characteristics.docx available at https://authorea.com/users/442311/ articles/542600-chemotherapy-induced-thrombocytopenia-in-ewing-sarcoma-implicationsand-potential-for-romiplostim-supportive-care

\section{Hosted file}

TABLE2- patient and disease related variables associated with CIT.docx available at 
https://authorea. com/users/442311/articles/542600-chemotherapy-induced-thrombocytopeniain-ewing-sarcoma-implications-and-potential-for-romiplostim-supportive-care

\section{Hosted file}

TABLE3- treatment related variables associated with CIT.docx available at https://authorea. com/users/442311/articles/542600-chemotherapy-induced-thrombocytopenia-in-ewing-sarcomaimplications-and-potential-for-romiplostim-supportive-care

\section{Response to maximum romiplostim dose:}

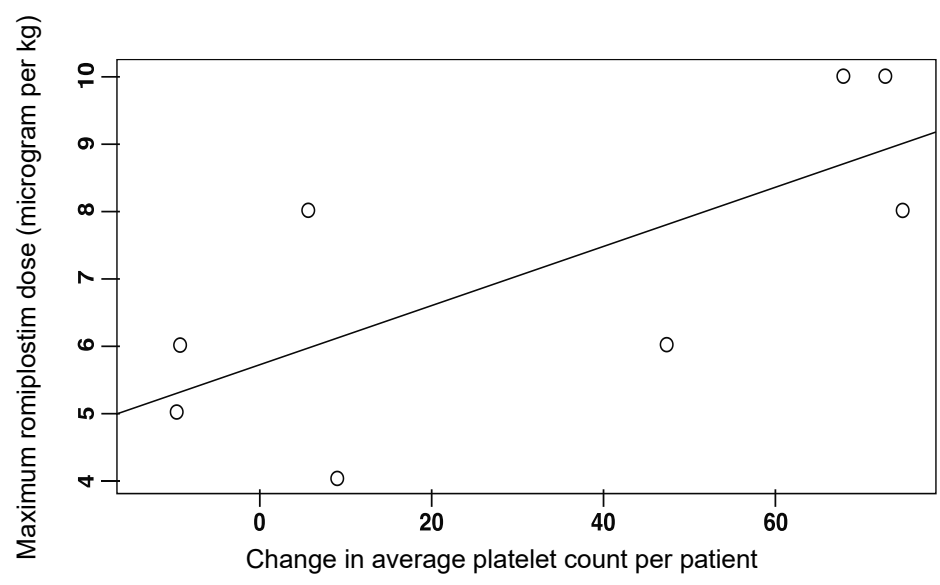

Figure 1: The correlation between max romiplostim dose and the change in the average platelet counts from baseline is $r=0.73(p=0.04)$. 